\title{
Severe depression is associated with increased microglial quinolinic acid in subregions of the anterior cingulate gyrus: Evidence for an immune-modulated glutamatergic neurotransmission?
}

Johann Steiner ${ }^{1,2^{*}}$, Martin Walter $^{1+}$, Tomasz Gos $^{1,3}$, Gilles J Guillemin ${ }^{4}$, Hans-Gert Bernstein ${ }^{1}$, Zoltán Sarnyai ${ }^{5}$, Christian Mawrin ${ }^{6}$, Ralf Brisch ${ }^{1}$, Hendrik Bielau', Louise Meyer zu Schwabedissen ${ }^{1}$, Bernhard Bogerts ${ }^{1}$ and Aye-Mu Myint ${ }^{1,7}$

\begin{abstract}
Background: Immune dysfunction, including monocytosis and increased blood levels of interleukin-1, interleukin-6 and tumour necrosis factor $\alpha$ has been observed during acute episodes of major depression. These peripheral immune processes may be accompanied by microglial activation in subregions of the anterior cingulate cortex where depression-associated alterations of glutamatergic neurotransmission have been described.
\end{abstract}

Methods: Microglial immunoreactivity of the N-methyl-D-aspartate (NMDA) glutamate receptor agonist quinolinic acid (QUIN) in the subgenual anterior cingulate cortex (SACC), anterior midcingulate cortex (AMCC) and pregenual anterior cingulate cortex ( $\mathrm{PACC}$ ) of 12 acutely depressed suicidal patients (major depressive disorder/MDD, $n=7$; bipolar disorder/BD, $n=5$ ) was analyzed using immunohistochemistry and compared with its expression in 10 healthy control subjects.

Results: Depressed patients had a significantly increased density of QUIN-positive cells in the SACC $(P=0.003)$ and the aMCC $(P=0.015)$ compared to controls. In contrast, counts of QUIN-positive cells in the PACC did not differ between the groups $(P=0.558)$. Post-hoc tests showed that significant findings were attributed to MDD and were absent in BD.

Conclusions: These results add a novel link to the immune hypothesis of depression by providing evidence for an upregulation of microglial QUIN in brain regions known to be responsive to infusion of NMDA antagonists such as ketamine. Further work in this area could lead to a greater understanding of the pathophysiology of depressive disorders and pave the way for novel NMDA receptor therapies or immune-modulating strategies.

\section{Background}

Recent studies have focused on the role of immune dysfunction in depression, and analogies to "cytokineinduced sickness behavior" have been established [1]. Sickness behavior is a coordinated set of adaptive behavioral changes that develop in affected individuals during

\footnotetext{
* Correspondence: johann.steiner@med.ovgu.de

† Contributed equally

${ }^{1}$ Department of Psychiatry, University of Magdeburg, Magdeburg, Germany Full list of author information is available at the end of the article
}

the course of an infection. Disease symptoms include lethargy, depression, failure to concentrate, anorexia, sleep disturbances, reduction in personal hygiene or social withdrawal, and are mediated by proinflammatory cytokines, such as interleukin-1 (IL-1), interleukin-6 (IL6) and tumor necrosis factor $\alpha$ (TNF $\alpha$ ) [1].

Previous research has suggested that these specific monocyte-derived cytokines are increased in the peripheral blood of acutely depressed patients [2-7] along with elevated monocyte counts [8,9]. Furthermore, 
lymphocyte and natural killer cell abnormalities have been described [10-12]. It is not yet clear, whether these changes in the peripheral blood are associated with corresponding neuroinflammatory responses and alterations in neurotransmission. Peripheral immune processes may be mirrored in the brains of patients with acute depression by microglial cells which represent the brain's mononuclear phagocyte system (MPS) [2,13]. Indeed, an increased density of microglia expressing human leukocyte antigen (HLA)-DR has recently been observed in the anterior midcingulate cortex (aMCC), the dorsolateral prefrontal cortex and the mediodorsal thalamus of suicidal patients with affective disorders [14]. However, this study of the surface marker HLA-DR did not suggest a mechanism of how modulation of neurotransmission is accomplished.

Quinolinic acid (QUIN), an endogenous modulator with agonistic properties on $\mathrm{N}$-methyl-D-aspartate (NMDA), which is produced by microglial cells, may serve as a potential candidate for such a link between immune and neurotransmitter changes in depression [13]. This hypothesis is based on the observation that the above mentioned proinflammatory cytokines induce a shift from serotonin synthesis to tryptophan metabolism via the kynurenine pathway in glial cells [1,15-17], which may ultimately lead to serotonin depletion and particularly an increased production of the metabolite QUIN (Figure 1). MPS cells, such as microglia, macrophages and monocytes, mainly produce the NMDA receptor agonist QUIN, while astrocytes synthesize the NMDA receptor antagonist kynurenic acid (KYNA) because they lack the enzyme kynurenine monoxygenase (KMO) [18-20]. Analyses of blood and cerebrospinal fluid revealed elevated QUIN levels in cytokine-induced depression and major depressive disorder (MDD) $[1,21,22]$, while an increase in KYNA production was related to schizophrenia [23-25].

These findings may connect immune pathologies to MPS activation in MDD. In addition to serotonin depletion, a direct glutamatergic mechanism has been suggested, which has recently been identified as an important target of antidepressant treatment [26]. In this context, the anterior cingulate cortex (ACC), with its region-specific NMDA and $\alpha$-amino-3-hydroxy-5methyl-4-isoxazolepropionic acid (AMPA) glutamate receptor profiles that cover functionally segregated areas, represents an important target region in the central nervous system, although investigations must

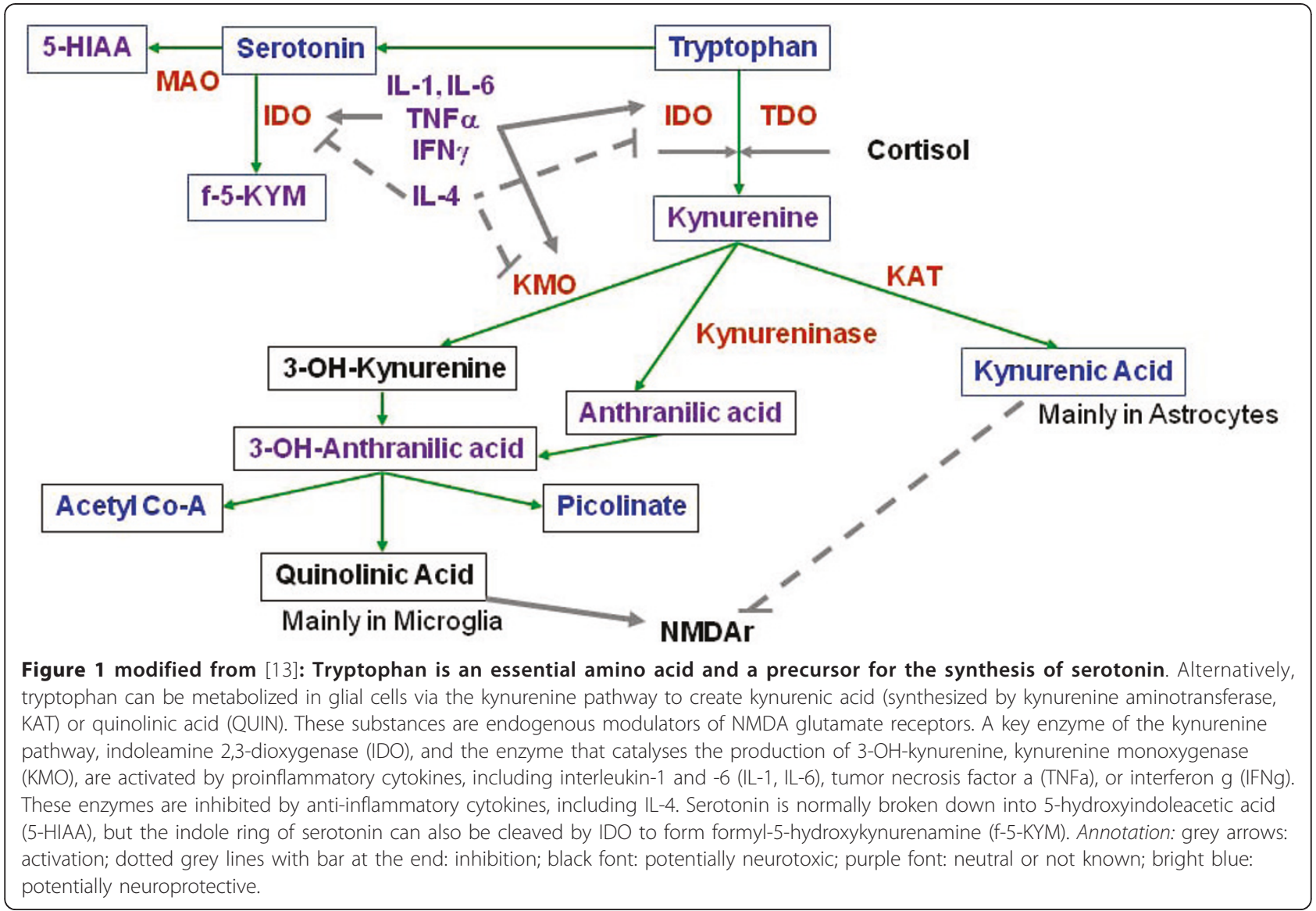


account for the histo-architectural diversity of this region [27]. The importance of the pregenual anterior cingulate cortex (pACC) in MDD is supported by the pronounced effects of the glutamate modulating NMDA antagonist ketamine on the improvement of clinical symptoms in treatment-resistant MDD patients [28], in which ketamine leads to an increase in glutamate concentration precisely in this region [29].

Therefore, we hypothesized that brain region-specific QUIN synthesis increases in depression and investigated this idea by analyzing the cellular and regional focus of QUIN immunoreactivity in the ACC of depressed suicidal MDD and bipolar disorder (BD) patients. An upregulated production of QUIN by microglia in regions with specific susceptibility to abnormal NMDA throughput would support the hypothesis of an upregulated MPS, and would close the gap between neurochemical imbalances and regional as well as functional in vivo imaging findings in depression. Only acutely ill patients were selected for the study, as previous studies of peripheral blood indicate that MPS activation and kynurenine pathway imbalances are associated with acute disease phases. In a postmortem study of chronically stable patients with MDD or BD, transient microglial changes may be missed.

\section{Methods}

\section{Human brain tissue}

Postmortem brains were obtained from the Magdeburg brain bank in accordance with the Declaration of Helsinki and the local institutional review board. Written consent was obtained from the next of kin. The donors were acutely depressed patients $(\mathrm{n}=12)$ who had committed suicide (mean age 51 years; 6 males, 6 females) and controls $(\mathrm{n}=10)$ with no neuropsychiatric illness (mean age 56 years; 5 males, 5 females). The cases were matched with respect to age, gender, duration of disease and autolysis time (Table 1). Patients had been diagnosed with either major depressive disorder (MDD; $\mathrm{n}=$ 7) or bipolar disorder (BD; $\mathrm{n}=5$ ).

Table 1 Demographic data of patients with depression $(n=12)$ and healthy control subjects $(n=10)$

\begin{tabular}{|c|c|c|c|c|c|}
\hline Case No. & Diagnosis (DSM-IV) & Gender & Age $(y)$ & Autolysis time (h) & Cause of death \\
\hline 1 & Depression, MDD & $\mathrm{F}$ & 53 & 47 & Suicide by electrocution \\
\hline 2 & Depression, MDD & $\mathrm{F}$ & 46 & 48 & Suicide by hanging \\
\hline 3 & Depression, MDD & $\mathrm{F}$ & 53 & 46 & Suicide by hanging \\
\hline 4 & Depression, MDD & $\mathrm{F}$ & 60 & 24 & Suicide by hanging \\
\hline 5 & Depression, MDD & $\mathrm{F}$ & 68 & 78 & Suicide by intoxication \\
\hline 6 & Depression, MDD & M & 35 & 15 & Suicide by wrist cutting \\
\hline 7 & Depression, MDD & M & 36 & 42 & Suicide by hanging \\
\hline 8 & Depression, BD & $\mathrm{F}$ & 46 & 4 & Suicide by intoxication \\
\hline 9 & Depression, BD & M & 47 & 24 & Suicide by wrist cutting \\
\hline 10 & Depression, BD & M & 57 & 48 & Suicide by strangulation \\
\hline 11 & Depression, BD & M & 60 & 24 & Suicide by hanging \\
\hline \multirow[t]{4}{*}{12} & Depression, BD & M & 53 & 24 & Suicide by hanging \\
\hline & Depression (ratio/mean \pm SD) & $6 \mathrm{~F} / 6 \mathrm{M}$ & $51 \pm 9$ & $35 \pm 24$ & \\
\hline & MDD $($ ratio/mean \pm SD $)$ & $5 F / 2 M$ & $50 \pm 12$ & $45 \pm 25$ & \\
\hline & $\mathrm{BD}($ ratio/mean $\pm \mathrm{SD})$ & $1 \mathrm{~F} / 4 \mathrm{MF}$ & $53 \pm 6$ & $19 \pm 10$ & \\
\hline 13 & Control & F & 48 & 48 & Status asthmaticus \\
\hline 14 & Control & $\mathrm{F}$ & 50 & 72 & Ruptured aortic aneurysm \\
\hline 15 & Control & $\mathrm{F}$ & 61 & 8 & Sudden death (reason unknown) \\
\hline 16 & Control & $\mathrm{F}$ & 61 & 24 & Heart failure (coronary heart disease) \\
\hline 17 & Control & $\mathrm{F}$ & 63 & 24 & Myocardial infarction \\
\hline 18 & Control & M & 56 & 48 & Retroperitoneal haemorrhage \\
\hline 19 & Control & M & 47 & 24 & Acute respiratory failure (aspiration) \\
\hline 20 & Control & M & 54 & 35 & Ruptured aortic aneurysm \\
\hline 21 & Control & M & 63 & 48 & Heart failure (after heart surgery) \\
\hline \multirow[t]{4}{*}{22} & Control & M & 54 & 24 & Pulmonary embolism \\
\hline & Controls (ratio/mean $\pm \mathrm{SD}$ ) & $5 \mathrm{~F} / 5 \mathrm{M}$ & $56 \pm 6$ & $35 \pm 18$ & \\
\hline & Statistic ( $P$ value) & $1.000^{\mathrm{a}}$ & $0.200^{b}$ & $0.954^{\mathrm{b}}$ & Control vs. Depression \\
\hline & Statistic ( $P$ value) & $0.214^{\mathrm{a}}$ & $0.422^{c}$ & $0.272^{c}$ & Control vs. MDD vs. BD \\
\hline
\end{tabular}

Abbreviations: BD bipolar disorder, MDD major depressive disorder, $\mathrm{F}$ female, $\mathrm{M}$ male, SD standard deviation, ${ }^{\mathrm{a}} \mathrm{chi}^{\mathrm{s}}{ }^{\mathrm{s} q u a r e}$ test, ${ }^{\mathrm{b}} \mathrm{t}$-test (Control vs. Depression) and ${ }^{\mathrm{C}} \mathrm{ANOVA}$ (Control vs. MDD vs. BD). 
The information used for clinical diagnoses was obtained by carefully studying the patients' clinical records and by structured interviews with physicians involved in patient treatment and with persons who either lived with or had frequent contact with the subjects before death. The DSM-IV axis I diagnosis of MDD and $\mathrm{BD}$ was established in consensus meetings of two psychiatrists (JS and $\mathrm{HB}$ ) using all available information from interviews and clinical records [30]. Brains with lifetime reports of substance abuse, dementia, neurological illness, severe trauma, or chronic terminal diseases known to affect the brain were excluded. Additionally, neuropathological changes due to neurodegenerative disorders, tumors, inflammatory, vascular, or traumatic processes identified by an experienced neuropathologist (CM) were excluded. The determination of suicide was made by a forensic pathologist (TG) and was verified based on the individual records. As summarized in Table 2 the mean daily doses of psychotropic medication taken by patients during the last 90 lifetime days were established according to the clinical files [31-33].

Tissue preparation was performed as described previously $[14,34]$. Briefly, brains were fixed in $8 \%$ phosphatebuffered formaldehyde ( $\mathrm{pH}$ 7.0) for three months. Subsequently, after separation of the brainstem and the cerebellum, the hemispheres were divided by coronal cuts into three bi-hemispherical coronal blocks comprising the frontal lobe anterior to the genu of the corpus callosum ("anterior" block), the fronto-temporo-parietal lobe extending the entire length of the corpus callosum ("middle" block) and the occipital lobe ("posterior" block). After embedding the brains in paraffin, serial coronal whole brain sections were cut $20 \mu \mathrm{m}$ in width and mounted.

\section{Region selection}

Sections for QUIN immunohistochemistry were anatomically selected corresponding to Brodmann's area (BA)
24' (anterior midcingulate cortex, aMCC), BA 25 (subgenual anterior cingulate cortex, sACC) and BA 24/32 (pregenual anterior cingulate cortex, pACC) for QUIN immunohistochemistry (Figure 2) [27,35]. We were able to study both subgenual and supracallosal areas in the same section. These two regions have similar receptor architectonics, in contrast to a more pregenual region of the ACC, which was covered by a second section. This method was possible given the suitable angulation of the coronal whole brain sections available in the Magdeburg brain bank.

The exact thickness of each section was determined by focusing on the upper and lower surfaces of the section and subtracting the $\mathrm{z}$-axis coordinate of the lower surface from that of the upper surface. The movements in the $\mathrm{z}$-axis were measured with a microcator, part of the Leica DM RB microscope (Leica, Gießen, Germany). The section thickness after histological procedures was $18.7 \pm 1.1 \mu \mathrm{m}($ mean $\pm \mathrm{SD})$.

\section{Immunohistochemistry}

Formalin-fixed tissue sections were deparaffinized, and antigen demasking was performed by boiling the sections for $4 \mathrm{~min}$ in $10 \mathrm{mM}$ citrate buffer ( $\mathrm{pH}$ 6.0). Preincubation with $1.5 \% \quad \mathrm{H}_{2} \mathrm{O}_{2}$ for 10 min to block endogenous peroxidase activity was followed by blocking non-specific binding sites with $10 \%$ normal goat serum for $60 \mathrm{~min}$ and repeated washings with PBS. Next, a polyclonal rabbit QUIN antibody was used (ab37106, Abcam, Cambridge, UK) at a dilution of 1:150 for $72 \mathrm{~h}$ at $4{ }^{\circ} \mathrm{C}$. Sections were then incubated with a biotinylated goat anti-rabbit secondary antibody (Amersham, Little Chalford, UK) for the streptavidin-biotin technique. Chromogen 3,3'-diaminobenzidine (DAB) and ammonium nickel sulfate were used to visualize the reaction product [36]. The specificity of the polyclonal rabbit primary antibody was confirmed by a loss of signal after

Table 2 Mean daily doses of psychotropic medication taken by patients during the last 90 lifetime days

\begin{tabular}{|c|c|c|c|c|c|}
\hline Case No. & $\begin{array}{c}\text { Antidepressants } \\
\text { (amitriptyline equivalents, } \mathrm{mg} \text { ) }\end{array}$ & $\begin{array}{c}\text { Neuroleptics } \\
\text { (chlorpromazine equivalents, } \mathrm{mg} \text { ) }\end{array}$ & $\begin{array}{c}\text { Benzodiazepines } \\
\text { (diazepam equivalents, } \mathrm{mg} \text { ) }\end{array}$ & $\begin{array}{l}\text { Carbamazepine } \\
\text { (mg) }\end{array}$ & $\begin{array}{l}\text { Lithium } \\
\text { (mg) }\end{array}$ \\
\hline 1 & 67 & 0 & 0 & 0 & 0 \\
\hline 2 & 124 & 109 & 0 & 0 & 0 \\
\hline 3 & 0 & 0 & 0 & 0 & 0 \\
\hline 4 & 100 & 400 & 0 & 0 & 0 \\
\hline 5 & 100 & 50 & 7.5 & 0 & 0 \\
\hline 6 & 0 & 0 & 0 & 0 & 0 \\
\hline 7 & 0 & 0 & 0 & 0 & 0 \\
\hline 8 & 133 & 327 & 3 & 0 & 558 \\
\hline 9 & 20 & 0 & 0 & 0 & 0 \\
\hline 10 & n.a. & n.a. & n.a. & n.a. & n.a. \\
\hline 11 & 0 & 125 & 10 & 0 & 750 \\
\hline 12 & 150 & 200 & 0 & 200 & 0 \\
\hline
\end{tabular}

Annotations: none of these patients was treated with valproate or lamotrigine; n.a. not available. 


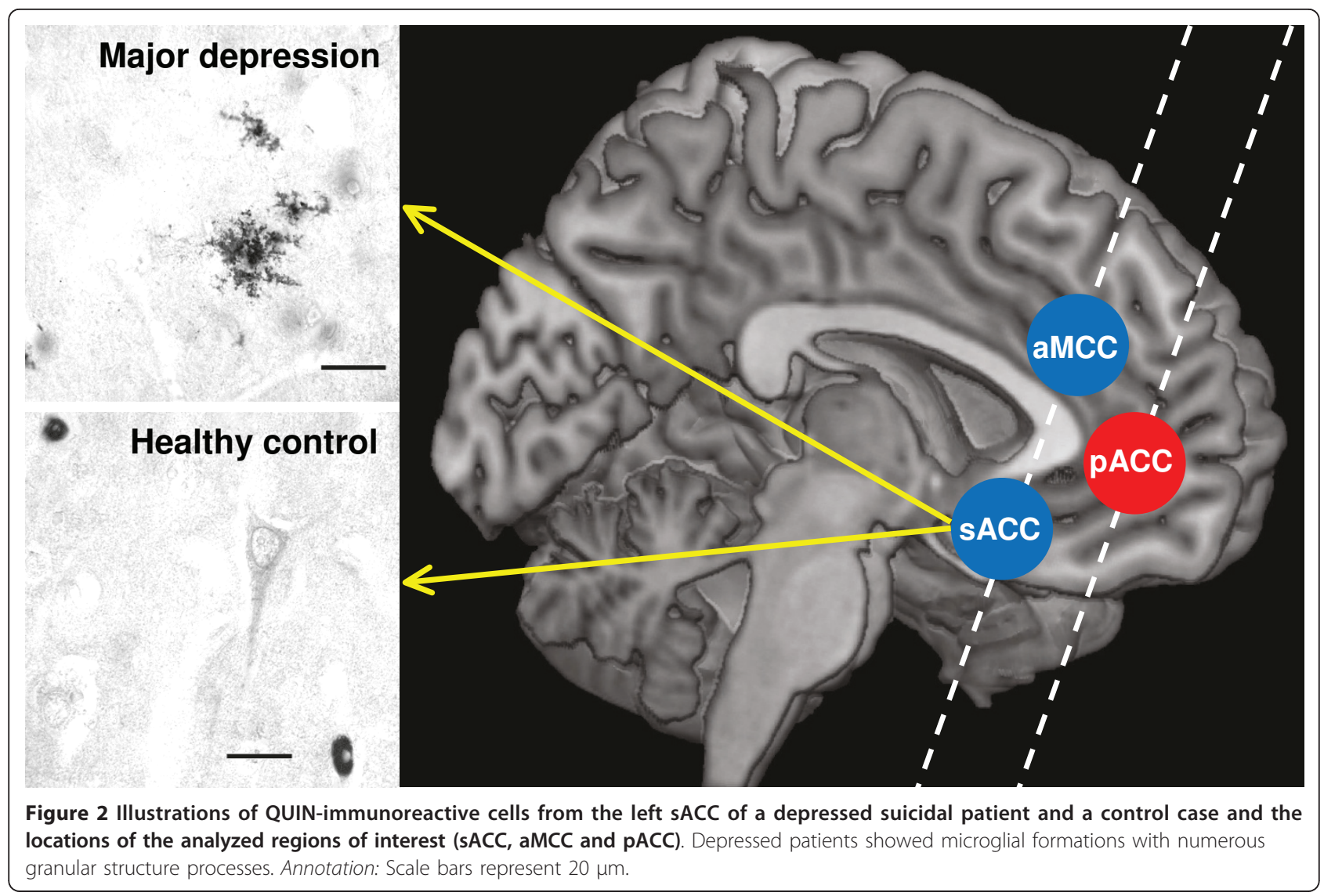

preabsorption of $2 \mathrm{ml}$ of the primary antibody solution (dilution 1:150) with $1 \mathrm{mg}$ QUIN (Sigma-Aldrich, Munich, Germany) for $24 \mathrm{~h}$ and by the supplier's ELISA competition experiments with QUIN, kynurenic acid and phenylalanine.

\section{Quantification}

Immunopositive cells were counted in the delineated brain regions listed above at 200x magnification (Olympus BH2, Olympus, Hamburg, Germany) by experimenters blind to the donors' diagnoses (TG and LMS). Evaluations were performed in two coronal sections per brain region of interest. The counting area was measured with the graphical analysis software Digitrace v. 2.10a (Imatec, Miesbach, Germany) using a SZX12 stereomicroscope (Olympus, Hamburg, Germany). The cytological classification of immunopositive cells as microglia, astrocytes, oligodendrocytes or neurons was performed according to established cytomorphological criteria [37]. Cells visibly located inside vessels were classified as monocytes; only cells that were clearly outside the vessels and situated in tissue were evaluated. Cell densities were calculated by dividing the cell number by the counting area multiplied by the section thickness $\left[\right.$ cells $\left./ \mathrm{mm}^{3}\right]$.

\section{Statistical analysis}

Statistical analyses were performed with the SPSS 15.0 program (Statistical Product and Service Solutions, Chicago, IL, USA). Demographic data were compared by the chi-square test, t-test and analysis of variance (ANOVA). QUIN data were not normally distributed, as indicated by the Kolmogorov-Smirnov test. Therefore, Spearman's rank correlation coefficient, the KruskalWallis $\mathrm{H}$ test and the Mann-Whitney $\mathrm{U}$ test were employed. These non-parametric tests were further used to explore potential confounds due to age, gender, duration of disease, method of suicide, autolysis or fixation time, and medication dosage.

\section{Results}

\section{Qualitative evaluation}

Strong QUIN immunoreactivity was found exclusively in vascular monocytes and microglial cells. In contrast, faint staining was only occasionally observed in fibers and other cell types, such as pyramidal neurons and astroglia. The immunoreactive microglia revealed different morphological features in healthy controls versus patients. In control subjects, we found mostly a smooth, ovoid or elongated cell form (Figure 2). In contrast, particularly in the aMCC and the sACC, the cortical grey 
matter of depressed patients revealed microglial forms with numerous granular structure processes (Figure 2), as previously demonstrated by Guillemin et al. in human tissue [38].

\section{Quantitative evaluation}

Comparing QUIN-immunopositive microglia between depressed patients and healthy controls revealed a region-specific pattern with group effects only in the aMCC and the sACC. Depressed patients had significantly increased QUIN-positive cells in the $\operatorname{sACC}(P=$ $0.003)$ and the aMCC $(P=0.015)$. In contrast, cell counts in the pACC did not differ between groups $(P=$ 0.558) (Figure 3a).

Post-hoc tests of diagnostic subgroups identified increased cell counts only for MDD patients. In these patients, QUIN-immunopositive microglia was increased compared to controls (sACC $P=0.003$, aMCC $P=$ 0.015) and compared to the subgroup of bipolar depressed cases (sACC $P=0.042$, aMCC $P=0.028$ ) (Figure $3 b)$. Notably, no significant increase was found in the pACC in either comparison. Diagnostic specificity

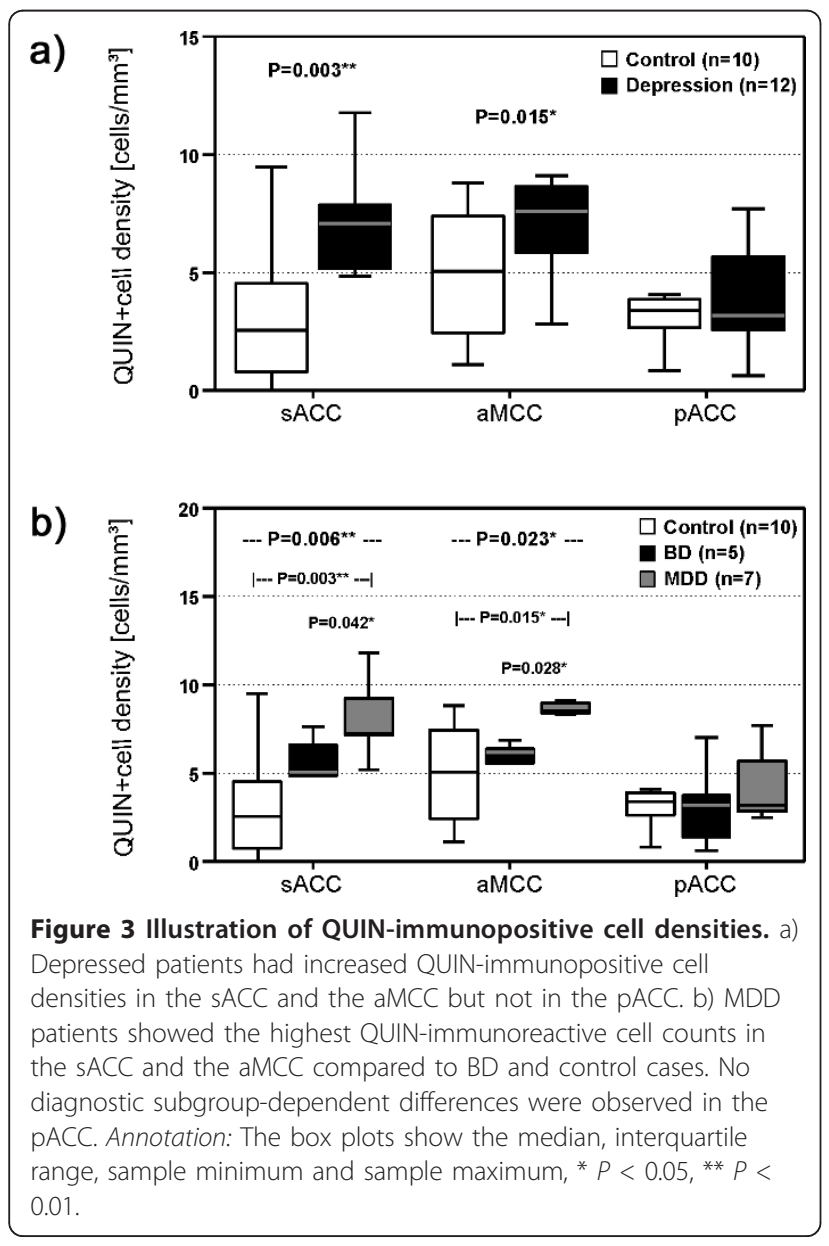

of the increases in MDD was further supported by the lack of any significant increase or decrease in QUINimmunopositive microglia cell counts in bipolar depressed patients when compared to healthy controls.

The reported effects were controlled for the potential confounding factors of age, gender, duration of disease, method of suicide, autolysis or fixation time, and medication dosage.

\section{Discussion}

To our knowledge, this is the first report of microglial QUIN expression in human brain during acute depressive episodes. An increase in QUIN-immunopositive microglia was specific to cingulate subregions with high NMDA receptor densities, like the sACC and the aMCC, but not the pACC, which shows a lower NMDA receptor expression. This increase in QUIN-immunoreactive microglial cell densities was found particularly in unipolar patients. With regard to BD less clear statements can be given. We observed a significant difference between MDD and BD, yet the BD group is also higher than the controls, though this is apparently not significant (Figure $3 b$ ). This could be due to the small number of specimens studied. The numeric increase in QUINimmunopositive cell counts was paralleled by the presence of microglial forms that displayed numerous granular structure processes in the proximity of neurons in the depressed group, supporting an interaction of inflammatory mechanisms and neurotransmission at the time of acute depressive episodes. These findings thus corroborate evidence for acute inflammatory microglial activation in depression, leading to increased levels of the NMDA receptor agonist QUIN in regions with corresponding receptor profiles that have been previously revealed as key structures in non-invasive imaging studies.

Increased levels of QUIN, which is also produced by macrophages and monocytes, have already been found in the blood and cerebrospinal fluid of subjects with cytokine-induced depression or MDD [1,21,22]. Thus, our result of increased microglial QUIN expression in suicidal MDD patients is in line with the hypothesis of a systemic MPS activation during acute disease phases of depression $[2-9,14]$. Due to the excitotoxic properties of QUIN, our findings are also supporting the neurodegeneration hypothesis of depression [15]. Therefore, our study provides insight into why immune- and glutamate-modulating therapies may be helpful for acutely ill suicidal patients suffering from depression. Potential candidate drugs include the tetracycline antibiotic minocycline, which inhibits microglial activation by blocking NF-kappa B nuclear translocation [39-42] or antiinflammatory inhibitors of cyclooxygenase-2 $[43,44]$. Furthermore, severely depressed suicidal patients may 
benefit from the administration of glutamate-modulating drugs, such as the NMDA receptor antagonist ketamine $[28,45,46]$.

It should be mentioned that Laugeray and colleagues observed reduced levels of the QUIN precursor 3-OHkynurenine $(3 \mathrm{HK})$ in the cingulate cortex and increased levels of $3 \mathrm{HK}$ in the striatum and the amygdala of mice using an unpredictable chronic mild-stress model for the induction of depressive-like symptoms [47]. The observation of reduced $3 \mathrm{HK}$ could be due to either reduced formation of $3 \mathrm{HK}$ or increased degradation of $3 \mathrm{HK}$ to QUIN, which would result in reduced $3 \mathrm{HK}$ level. Since QUIN was not directly measured in this study, a translational validation of these converging results remains subject to future studies. A general drawback of animal studies is that it is unclear if animal models adequately reflect the pathophysiology of human MDD or BD. Moreover, an analysis of ACC subregions was not undertaken in this study, and direct correspondence of subregions in primates and humans differ considerably to those found in rodents. Therefore, the implications on regional glutamatergic throughput in depression, as a function of local NMDA and AMPA receptor profiles, remain difficult to interpret in animal studies.

We have shown that abnormal NMDA receptor function related to microglial activation is highly dependent on the location in the ACC in humans. Non-invasive studies have led to similar distinctions of abnormal cingulate cortex activation in MDD. While sACC hyperactivity has been postulated in a number of studies, the pACC has been less consistently characterized. Grimm et al. [48] found a reduced deactivation during a task study, reflected in smaller negative BOLD responses in a sample of severely depressed patients; this functional deficit was accompanied by decreased pACC glutamate and glutamine levels, which are correlated with the severity of clinical depressive symptoms [49-51]. Moreover, these glutamatergic deficits have been related to anhedonia and abnormal functional activations in the pACC in humans [52]. Our finding of relatively increased QUIN immunoreactivity, which is potentially associated with serotonin depletion due to changes in the kynurenine pathway, would thus be consistent with the relative hyperactivation in the sACC. The sACC is also a putative target of deep brain stimulation. Importantly, the metabolic activity after deep brain stimulation in the sACC, as measured by positron emission tomography, shows a reduction in hyperactivity similar to a region bordering the aMCC and the pACC [53].

Specifically increased concentrations of the NMDA receptor agonist QUIN in the aMCC and the sACC may also directly contribute to the disturbed balance in glutamatergic throughput, which could explain the rapid onset of antidepressant effects after ketamine [28,46]. According to Salvadore et al. [54], activity bordering the pACC does indeed predict the responsiveness towards ketamine treatment; therefore, our finding may represent a histopathological surrogate. As shown by Vollenweider and Kometer [55], similar metabolic changes can be found in the sACC and aMCC upon acute ketamine administration. Therefore, the anatomical patterns of such pharmacological challenges fit the observed pattern of microglial histopathology.

The present study has certain limitations that need to be considered: (1) our findings are based on a relatively small number of MDD and BD cases and must be confirmed in a larger sample size; (2) it was not possible to track data on drug exposure or the history of inflammation and infection across the patients' entire life spans, as we could only collect data on psychotropic medication in the three months prior to death; (3) the present study enables us to draw conclusions about the cellular QUIN content, but not released or secreted QUIN in the extracellular space, which potentially interferes with glutamatergic neurotransmission; (4) it remains unclear if increased QUIN immunoreactivity in microglial cells is caused by increased synthesis or reduced degradation of QUIN. Future studies in frozen tissue may address this question by measuring different kynurenine pathway metabolites using high-performance liquid chromatography (HPLC) or mass spectrometry (MS). (5) It is currently uncertain if drugs like glibenclamide, nifedipine, metoprolol, or theophylline which have been applied in five of the control subjects may influence microglial QUIN expression.

\section{Conclusion}

Here we present the first study providing evidence that supports a disease-related upregulation of microglial QUIN in depressive disorders, particularly in brain regions known to be responsive to infusion of NMDA antagonists such as ketamine [55]. These results add a novel link to the immune $[1,26]$ and neurodegeneration [15] hypotheses of depression. Further work in this area could lead to a greater understanding of the pathophysiology of depressive disorders and pave the way for identification of novel biomarkers and therapeutic strategies targeting specific disease subtypes.

\section{Acknowledgements}

Pembroke College (University of Cambridge, Cambridge, UK) has invited JS for a Visiting Scholarship. This work was supported in part by grants of the Stanley Medical Research Foundation to BB and JS (Grant No. 07R-1832), the Commission of European Communities 7th Framework Program

Collaborative Project "MOODINFLAME" to AMM (Grant No. 22963), and the DFG-SFB 779 to BB and MW. We are grateful to Henrik Dobrowolny for his skilful assistance in statistical analysis. Gabi Meyer-Lotz and Kathrin Paelchen provided excellent technical assistance. 


\section{Author details}

'Department of Psychiatry, University of Magdeburg, Magdeburg, Germany.

${ }^{2}$ Pembroke College, University of Cambridge, Cambridge, UK. ${ }^{3}$ Institute of Forensic Medicine, Medical University of Gdańsk, Gdańsk, Poland.

${ }^{4}$ Department of Pharmacology, University of New South Wales, Sydney, Australia. ${ }^{5}$ Department of Pharmacology, University of Cambridge, Cambridge, UK. Institute of Neuropathology, University of Magdeburg, Magdeburg, Germany. ${ }^{7}$ Department of Psychiatry, University of Munich, Munich, Germany.

\section{Authors' contributions}

The work presented here has been carried out in collaboration between all authors. JS, MW, TG, GJG, HGB, BB and AMM have designed the study. CM has done the routine neuropathological examination. DSM-IV axis I diagnosis of MDD and BD was established in consensus meetings of JS and HB. JS, TG, HGB and LMS carried out the laboratory experiments. JS, TG, GJG, LMS and AMM analyzed the data and interpreted the results. RB was involved in the creation of figures. JS, MW, TG, ZS, BB and AMM wrote the manuscript. All authors have read and approved the final version of the manuscript.

\section{Competing interests}

The authors declare that they have no competing interests.

Received: 30 June 2011 Accepted: 10 August 2011

Published: 10 August 2011

\section{References}

1. Dantzer R, O'Connor JC, Freund GG, Johnson RW, Kelley KW: From inflammation to sickness and depression: when the immune system subjugates the brain. Nat Rev Neurosci 2008, 9:46-56.

2. Drexhage RC, Knijff EM, Padmos RC, Heul-Nieuwenhuijzen L, Beumer W, Versnel MA, Drexhage HA: The mononuclear phagocyte system and its cytokine inflammatory networks in schizophrenia and bipolar disorder. Expert Rev Neurother 2010, 10:59-76.

3. Myint AM, Leonard BE, Steinbusch HW, Kim YK: Th1, Th2, and Th3 cytokine alterations in major depression. J Affect Disord 2005, 88:167-173.

4. Kaestner F, Hettich M, Peters M, Sibrowski W, Hetzel G, Ponath G, Arolt V, Cassens U, Rothermundt M: Different activation patterns of proinflammatory cytokines in melancholic and non-melancholic major depression are associated with HPA axis activity. J Affect Disord 2005, 87:305-311.

5. Miller AH, Maletic $V$, Raison CL: Inflammation and its discontents: the role of cytokines in the pathophysiology of major depression. Biol Psychiatry 2009, 65:732-741.

6. Zorrilla EP, Luborsky L, McKay JR, Rosenthal R, Houldin A, Tax A, McCorkle R, Seligman DA, Schmidt K: The relationship of depression and stressors to immunological assays: a meta-analytic review. Brain Behav Immun 2001, 15:199-226.

7. Padmos RC, Hillegers MH, Knijff EM, Vonk R, Bouvy A, Staal FJ, de Ridder D, Kupka RW, Nolen WA, Drexhage HA: A discriminating messenger RNA signature for bipolar disorder formed by an aberrant expression of inflammatory genes in monocytes. Arch Gen Psychiatry 2008, 65:395-407.

8. Seidel A, Arolt V, Hunstiger M, Rink L, Behnisch A, Kirchner H: Major depressive disorder is associated with elevated monocyte counts. Acta Psychiatr Scand 1996, 94:198-204.

9. Maes M, Van der Planken M, Stevens WJ, Peeters D, DeClerck LS, Bridts CH, Schotte C, Cosyns P: Leukocytosis, monocytosis and neutrophilia: hallmarks of severe depression. J Psychiatr Res 1992, 26:125-134.

10. Irwin M, Smith TL, Gillin JC: Low natural killer cytotoxicity in major depression. Life Sci 1987, 41:2127-2133.

11. Kronfol Z, House JD: Depression, hypothalamic-pituitary-adrenocortical activity, and lymphocyte function. Psychopharmacol Bull 1985, 21:476-478.

12. Maes M, Lambrechts J, Suy E, Vandervorst C, Bosmans E: Absolute number and percentage of circulating natural killer, non-MHC-restricted T cytotoxic, and phagocytic cells in unipolar depression. Neuropsychobiology 1994, 29:157-163.

13. Steiner J, Bogerts B, Sarnyai Z, Walter M, Gos T, Bernstein HG, Myint AM: Bridging the gap between the immune and glutamate hypotheses of schizophrenia and major depression: Potential role of glial NMDA receptor modulators and impaired blood-brain barrier integrity. World $J$ Biol Psychiatry 2011.
14. Steiner J, Bielau H, Brisch R, Danos P, Ullrich O, Mawrin C, Bernstein HG, Bogerts B: Immunological aspects in the neurobiology of suicide: Elevated microglial density in schizophrenia and depression is associated with suicide. J Psychiatr Res 2008, 42:151-157.

15. Myint AM, Kim YK: Cytokine-serotonin interaction through IDO: a neurodegeneration hypothesis of depression. Med Hypotheses 2003, 61:519-525.

16. Connor TJ, Starr N, O'Sullivan JB, Harkin A: Induction of indolamine 2,3dioxygenase and kynurenine 3-monooxygenase in rat brain following a systemic inflammatory challenge: a role for IFN-gamma? Neurosci Lett 2008, 441:29-34.

17. Hu B, Hissong BD, Carlin JM: Interleukin-1 enhances indoleamine 2,3dioxygenase activity by increasing specific mRNA expression in human mononuclear phagocytes. J Interferon Cytokine Res 1995, 15:617-624.

18. Guillemin GJ, Smythe G, Takikawa O, Brew BJ: Expression of indoleamine 2,3-dioxygenase and production of quinolinic acid by human microglia, astrocytes, and neurons. Glia 2005, 49:15-23.

19. Guillemin GJ, Kerr SJ, Smythe GA, Smith DG, Kapoor V, Armati PJ, Croitoru J, Brew BJ: Kynurenine pathway metabolism in human astrocytes: a paradox for neuronal protection. J Neurochem 2001, 78:842-853.

20. Guillemin GJ, Smith DG, Kerr SJ, Smythe GA, Kapoor V, Armati PJ, Brew BJ: Characterisation of kynurenine pathway metabolism in human astrocytes and implications in neuropathogenesis. Redox Rep 2000, 5:108-111.

21. Myint AM, Kim YK, Verkerk R, Scharpe S, Steinbusch H, Leonard B: Kynurenine pathway in major depression: evidence of impaired neuroprotection. J Affect Disord 2007, 98:143-151.

22. Raison CL, Dantzer R, Kelley KW, Lawson MA, Woolwine BJ, Vogt G, Spivey JR, Saito K, Miller AH: CSF concentrations of brain tryptophan and kynurenines during immune stimulation with IFN-alpha: relationship to CNS immune responses and depression. Mol Psychiatry 2010, 15:393-403.

23. Erhardt S, Blennow K, Nordin C, Skogh E, Lindstrom LH, Engberg G: Kynurenic acid levels are elevated in the cerebrospinal fluid of patients with schizophrenia. Neurosci Lett 2001, 313:96-98.

24. Nilsson LK, Linderholm KR, Engberg G, Paulson L, Blennow K, Lindstrom LH, Nordin C, Karanti A, Persson P, Erhardt S: Elevated levels of kynurenic acid in the cerebrospinal fluid of male patients with schizophrenia. Schizophr Res 2005, 80:315-322.

25. Linderholm KR, Skogh E, Olsson SK, Dahl ML, Holtze M, Engberg G, Samuelsson M, Erhardt S: Increased Levels of Kynurenine and Kynurenic Acid in the CSF of Patients With Schizophrenia. Schizophr Bull 2010.

26. Sanacora G, Zarate CA, Krystal JH, Manji HK: Targeting the glutamatergic system to develop novel, improved therapeutics for mood disorders. Nat Rev Drug Discov 2008, 7:426-437.

27. Palomero-Gallagher N, Vogt BA, Schleicher A, Mayberg HS, Zilles K: Receptor architecture of human cingulate cortex: evaluation of the fourregion neurobiological model. Hum Brain Mapp 2009, 30:2336-2355.

28. Zarate CA, Singh JB, Carlson PJ, Brutsche NE, Ameli R, Luckenbaugh DA, Charney DS, Manji HK: A randomized trial of an N-methyl-D-aspartate antagonist in treatment-resistant major depression. Arch Gen Psychiatry 2006, 63:856-864.

29. Rowland $L M$, Bustillo JR, Mullins $P G$, Jung $R E$, Lenroot $R$, Landgraf $E$, Barrow R, Yeo R, Lauriello J, Brooks WM: Effects of ketamine on anterior cingulate glutamate metabolism in healthy humans: a 4-T proton MRS study. Am J Psychiatry 2005, 162:394-396.

30. APA: Diagnostic and Statistical Manual of Mental Disorders, 4th revised edition (DSM-IV-TR). 4 edition. Washington, DC: American Psychiatric Press; 2000.

31. Bollini P, Pampallona S, Tibaldi G, Kupelnick B, Munizza C: Effectiveness of antidepressants. Meta-analysis of dose-effect relationships in randomised clinical trials. Br J Psychiatry 1999, 174:297-303.

32. Rey MJ, Schulz P, Costa C, Dick P, Tissot R: Guidelines for the dosage of neuroleptics. I: Chlorpromazine equivalents of orally administered neuroleptics. Int Clin Psychopharmacol 1989, 4:95-104.

33. Perry PJ, Alexander B: Sedative/hypnotic dependence: patient stabilization, tolerance testing, and withdrawal. Drug Intell Clin Pharm 1986, 20:532-537.

34. Steiner J, Mawrin C, Ziegeler A, Bielau H, Ullrich O, Bernstein HG, Bogerts B: Distribution of HLA-DR-positive microglia in schizophrenia reflects impaired cerebral lateralization. Acta Neuropathol 2006, 112:305-316.

35. Mai JK, Assheuer J, Paxinos G: Atlas of the Human Brain. 2 edition. San Diego: Academic Press; 2003. 
36. Hsu SM, Soban E: Color modification of diaminobenzidine (DAB) precipitation by metallic ions and its application for double immunohistochemistry. J Histochem Cytochem 1982, 30:1079-1082.

37. Polak M, Haymaker W, Johnson JE, D'Amelio F: Neuroglia and their reactions. In Histology and Histopathology of the Nervous System. Volume 1. Edited by: Haymaker W, Adams RD. Springfield: Charles C. Thomas Publishing; 1982:363-480

38. Guillemin GJ, Kerr SJ, Brew BJ: Involvement of quinolinic acid in AIDS dementia complex. Neurotox Res 2005, 7:103-123.

39. Miyaoka T, Yasukawa R, Yasuda H, Hayashida M, Inagaki T, Horiguchi J: Possible antipsychotic effects of minocycline in patients with schizophrenia. Prog Neuropsychopharmacol Biol Psychiatry 2007, 31:304-307.

40. Molina-Hernandez M, Tellez-Alcantara NP, Perez-Garcia J, Olivera-Lopez Jl, Jaramillo-Jaimes MT: Antidepressant-like actions of minocycline combined with several glutamate antagonists. Prog Neuropsychopharmacol Biol Psychiatry 2008, 32:380-386.

41. Pae CU, Marks DM, Han C, Patkar AA: Does minocycline have antidepressant effect? Biomed Pharmacother 2008, 62:308-311.

42. Levkovitz Y, Mendlovich S, Riwkes S, Braw Y, Levkovitch-Verbin H, Gal G, Fennig S, Treves I, Kron S: A double-blind, randomized study of minocycline for the treatment of negative and cognitive symptoms in early-phase schizophrenia. J Clin Psychiatry 2010, 71:138-149.

43. Akhondzadeh S, Tabatabaee M, Amini H, Ahmadi Abhari SA, Abbasi SH, Behnam B: Celecoxib as adjunctive therapy in schizophrenia: a doubleblind, randomized and placebo-controlled trial. Schizophr Res 2007, 90:179-185.

44. Müller N: COX-2 inhibitors as antidepressants and antipsychotics: clinical evidence. Curr Opin Investig Drugs 2010, 11:31-42.

45. Price RB, Nock MK, Charney DS, Mathew SJ: Effects of intravenous ketamine on explicit and implicit measures of suicidality in treatmentresistant depression. Biol Psychiatry 2009, 66:522-526.

46. Diazgranados N, Ibrahim L, Brutsche NE, Newberg A, Kronstein P, Khalife S, Kammerer WA, Quezado Z, Luckenbaugh DA, Salvadore G, MachadoVieira R, Manji HK, Zarate CA Jr: A randomized add-on trial of an $\mathrm{N}$ methyl-D-aspartate antagonist in treatment-resistant bipolar depression. Arch Gen Psychiatry 2010, 67:793-802.

47. Laugeray A, Launay JM, Callebert J, Surget A, Belzung C, Barone PR: Peripheral and cerebral metabolic abnormalities of the tryptophankynurenine pathway in a murine model of major depression. Behav Brain Res 2010, 210:84-91.

48. Grimm S, Ernst J, Boesiger P, Schuepbach D, Boeker H, Northoff G: Reduced negative BOLD responses in the default-mode network and increased self-focus in depression. World J Biol Psychiatry 2011.

49. Auer DP, Putz B, Kraft E, Lipinski B, Schill J, Holsboer F: Reduced glutamate in the anterior cingulate cortex in depression: an in vivo proton magnetic resonance spectroscopy study. Biol Psychiatry 2000, 47:305-313.

50. Rosenberg DR, Macmaster FP, Mirza Y, Smith JM, Easter PC, Banerjee SP, Bhandari R, Boyd C, Lynch M, Rose M, Ivey J, Villafuerte RA, Moore GJ, Renshaw P: Reduced anterior cingulate glutamate in pediatric major depression: a magnetic resonance spectroscopy study. Biol Psychiatry 2005, 58:700-704.

51. Horn DI, Yu C, Steiner J, Buchmann J, Kaufmann J, Osoba A, Eckert U, Zierhut KC, Schiltz K, He H, Biswal B, Bogerts B, Walter M: Glutamatergic and resting-state functional connectivity correlates of severity in major depression-the role of pregenual anterior cingulate cortex and anterior insula. Front Syst Neurosci 2010, 4:10.

52. Walter M, Henning A, Grimm S, Beck J, Schulte RF, Dydak U, Boeker H, Boesinger $\mathrm{P}$, Northoff $\mathrm{G}$ : The relationship between aberrant neuronal activation patterns in the pregenual anterior cingulate, altered glutamatergic metabolism and anhedonia in Major Depression. Arch Gen Psychiatry 2009, 40:1482-1494

53. Ressler KJ, Mayberg HS: Targeting abnormal neural circuits in mood and anxiety disorders: from the laboratory to the clinic. Nat Neurosci 2007, 10:1116-1124.

54. Salvadore G, Cornwell BR, Sambataro F, Latov D, Colon-Rosario V, Carver F, Holroyd T, DiazGranados N, Machado-Vieira R, Grillon C, Drevets WC Zarate CA Jr: Anterior cingulate desynchronization and functional connectivity with the amygdala during a working memory task predict rapid antidepressant response to ketamine. Neuropsychopharmacology 2010, 35:1415-1422.
55. Vollenweider FX, Kometer M: The neurobiology of psychedelic drugs: implications for the treatment of mood disorders. Nat Rev Neurosci 2010, 11:642-651.

doi:10.1186/1742-2094-8-94

Cite this article as: Steiner et al: Severe depression is associated with increased microglial quinolinic acid in subregions of the anterior cingulate gyrus: Evidence for an immune-modulated glutamatergic neurotransmission? Journal of Neuroinflammation 2011 8:94.

\section{Submit your next manuscript to BioMed Central and take full advantage of:}

- Convenient online submission

- Thorough peer review

- No space constraints or color figure charges

- Immediate publication on acceptance

- Inclusion in PubMed, CAS, Scopus and Google Scholar

- Research which is freely available for redistribution

Submit your manuscript at www.biomedcentral.com/submit
Biomed Central 